\title{
First Season's Progress Report on Vegetation Mapping of Grand Teton National Park
}

\author{
G.P. JONES $\uparrow$ D.H. EHLE \\ WYOMING NATURAL DIVERSITY DATABASE \\ UNIVERSITY OF WYOMING + LARAMIE
}

\section{$\uparrow \quad$ INTRODUCTION}

The National Park Service and the USGS Biological Resources Division have jointly established a program to map the vegetation in all of the Park Service's units with roughly the same methodology and using the same vegetation classification scheme. Grand Teton National Park in Wyoming has been selected for mapping in 2002 and 2003 as part of this national program. At Grand Teton National Park, the Bureau of Reclamation will interpret aerial photos and map the vegetation. The entities mapped by the Bureau will be related to vegetation types from a classification to be produced by NatureServe, an organization representing natural heritage programs and conservation data centers throughout North and Central America. The data on which the vegetation classification is based will be collected by the staff from the Wyoming Natural Diversity Database, working with National Park Service and NatureServe scientists.

In conjunction with the vegetation classification and mapping, Park Service personnel will produce a model to predict fuel loads throughout the Park. The model will predict amounts and types of fuel in the vegetation classification units, and will elucidate the relationship between fuel loads and variables such as slope, aspect, and elevation.

Field work for the Grand Teton National Park Vegetation Mapping Project is to be conducted over three summers. The effort in the first two summers will be dedicated to vegetation data collection, and the third summer will be dedicated to on-the-ground accuracy assessment of the preliminary vegetation map created by the photo interpreters.

\section{$\uparrow \quad$ Methods}

Three different sampling methods have been developed for collecting information on the vegetation of the Park: modified-Whittaker vegetation sample plots, detailed descriptions, and observation points. Modified-Whittaker plots yield quantitative information on the amounts of vascular plant species present in the vegetation at sample points, and this information will provide the foundation for the quantitative analysis used to produce the vegetation classification. Detailed descriptions from additional sampling points yield semi-quantitative information on composition and structure of the vegetation that will augment the more-detailed information from the modified-Whittaker plots. The information from both of these types of samples also will help the photo interpreters in describing map units. Observation points will be used to describe the vegetation in general terms, and will indicate which vegetation types are present in the units of the vegetation map.

The modified-Whittaker vegetation sampling plots will also be the mechanism for collecting the data to be used by Park Service personnel in modelling fuel loads in different vegetation types across the Park. 


\section{$\uparrow \quad$ Results from the First Field Season}

The summer of 2002 was the first year of vegetation data collection. One-hundred sixty-three modified-Whittaker vegetation sampling plots, three detailed descriptions in wetlands, and 73 observation points were sampled in the Park, primarily in the sagebrush shrublands, low- and intermediateelevation forests and woodlands, and riparian shrublands and forests. Some 5,400 plant specimens were collected from vegetation sampling plots for positive identification of the taxa in the plots and for voucher specimens.

When possible, the vegetation types encountered during the field work were assigned a provisional association name from the list of associations in the National Vegetation Classification System. Ninety vegetation types were assigned an association with confidence, 36 were assigned with uncertainty to an association with uncertainty, and 41 could not be assigned a plant association. Whenever possible, associations named in the National Vegetation Classification System (NVCS) was considered the final authority, although other sources were used when appropriate. 